\title{
A Case Study on Workers' Perception about Workstation and its Impact on their Health in Jack Fruit Processing Enterprise
}

\author{
V. Vijaya Lakshmi ${ }^{1^{*}}$ and J. Deepika ${ }^{2}$ \\ AICRP-Home Science, Professor Jayashankar Telangana State Agricultural University, \\ Rajendranagar mandal, Hyderabad, 500030, Telangana, India \\ *Corresponding author
}

\section{A B S T R A C T}

\section{Keywords \\ Perception, Workstation, Health, Jack fruit processing enterprise \\ Article Info \\ Accepted: \\ 15 November 2018 \\ Available Online: \\ 10 December 2018}

A case study was conducted in Hyderabad city on the worker's perception about their workstation and its impact on health in jack fruit processing enterprise. It was 18 years old enterprise run by the family members and processing jack husk, and jack pieces for selling across the country through retail stores. It was found that environmental parameters were not comfortable for the workers and were experience low back pain due to mismatch between the anthropometric dimensions and machinery height. Other reasons were repetitive nature of work and maintaining awkward postures and persistent as the enterprise was being run throughout the year. The study implies that there is a scope for improvement in the workstation design.

\section{Introduction}

Jackfruit (Artocarpus heterophyllus Lam.) is a widely found tropical fruit and perhaps the most widespread and useful fruit in the important genus Artocarpus. It has been cultivated since prehistoric times and has naturalized in many parts of the tropics, particularly in Southeast Asia, where it is an important crop of India, Bangladesh, Burma, China, Sri Lanka, Malaysia, Indonesia, Thailand and Philippines. It is also grown in parts of Africa, Brazil, Suriname, The Caribbean, Florida and Australia (Elevitch and Manner, 2006).
Jack fruit is a multipurpose species, providing food, fuel, timber and medicinal extracts (Ajayi, 2008). It is used to prepare squash, nectar, fruit bars, jam, jelly, canned bulbs, candy, dehydrated bulbs, etc., The bulk of the ripe fruit is eaten fresh. The fruit bears seed that represents $15-18 \%$ of the fruit weight. The seed contains around 55\% moisture and is a good source of starch and protein. About $50 \%$ of the fruit protein consists of lectins named jacalin that has an adverse effect in the digestive tract. The seed therefore needs to be cooked or processed for consumption. Jack fruit is a highly fibrous fruit. It has a thick wasted skin enclosing seeded fruit pods to 
which also adhere lots of fibrous tissue. Peeling and cleaning of the fruit to make it fit for processing is a difficult laborious process. In the jack fruit enterprise, the health of the workers may be exposed to the hazards such as the work-related musculoskeletal disorders. Normally, the injuries happen either at the muscles, tendons, nerves, blood vessel or ligaments. Musculoskeletal disorder (MSDs) may occur because of continuously performing repetitive tasks, working in repeated and sustained or difficult postures, performing strenuous physical work, and using forceful exertion. To improve the productions for higher profit, workers' productivity is important. Work productivity as an indicator has been a general subject for examination in several studies on musculoskeletal disorders that influence the workers condition. If the workers facing health problem, it indicates that the losses faced by the enterprise. Heavy lifting and awkward work postures are the physical working condition that relate with sick-leave. As the condition of the workers affects the productivity, hence the worker needs to have a comfortable workplace which is ideally free from hazards.

Logeswari et al., (2013) studied on musculoskeletal discomforts in papad industry. One hundred and fifty papad industry workers were randomly selected for the study in Madurai district. During the survey, the findings of the study revealed that eight one per cent of the workers were female and ninety five per cent of the workers suffered with low back pain followed by neck $(89 \%)$ and shoulder pain $(77 \%)$. Extreme level of discomfort $(59 \%)$ was faced by the workers in lower back whereas twenty one per cent indicated severe discomforts. Additionally, neck pain revealed that one-fourth of the workers had extreme discomfort as against forty six per cent who had severe discomfort. The study concluded that the postures adopted in the papad making industries may be the reason for MSDs.

Tiwari (2015) conducted a study on situational analysis of occupational health issues of restaurant and dhaba workers. Questionnaire survey of 50 subjects suggested that only $14 \%$ considered that their occupation poses health hazards while only $16 \%$ mentioned that they have provision for health care at their workplace. The study also revealed that majority $(70 \%)$ of the workers was resorting to traditional methods in case of illness while only $30 \%$ said that they use a piece of cloth to prevent inhalation of smoke near stoves. This study suggested that the dhaba workers are at risk of several occupational hazards which is further increased by the poor working conditions and lack of awareness about the protective measures.

Fazi et al., (2016) studied on identification of current problems related to ergonomic in food production process, to analyse the actual production data by using Rapid Upper Limb Assessment and Rapid Entire Body Assessment (REBA) and to recommend the ergonomic workplace environment based on the condition of the study. The study was done at a small and medium enterprises (SME) food production company in the klang valley of Malaysia. The condition of the workers affects the productivity of the company due to workers' health deficiency. From the findings, the workers were exposed to the awkward postures which lead to the work-related musculoskeletal disorders (WMSDs). The best height of the worker is $155 \mathrm{~cm}$ to $160 \mathrm{~cm}$ at the study area (critical area) to prevent the worker from WMSDs. The results showed that the workers were exposed to the WMSDs which caused high absenteeism among the workers in different level of risks.

Priya et al., (2017) conducted a study to find out the prevalence of musculoskeletal 
disorders (MSDs) in restaurant workers which included waiters and chefs. The study used the Modified Nordic Questionnaire to find out the most frequently affected body part, whether their work was affected due to their problem in last 12 months and if they had any problem in the last seven days. The result showed that $90 \%$ of the workers suffered from an MSD of which wrist $(27 \%)$ and shoulder $(20 \%)$ was maximally involved followed by lower back $(10 \%)$ and knee pain $(10 \%)$. This was due to their respective job demands where both the work profiles demanded for maximum upper limb use.

Vijaya Lakshmi et al., (2018) conducted a study on impact of workstation on health of handloom weavers in Nalgonda district. Descriptive cum experimental research design was adopted. An interview schedule was used to elicit information from 15 male and 15 female weavers who were selected by purposive sampling technique. The results of the study revealed that while working nearly 83.3 per cent of the workers had felt that their work station did not permit them to have full range of movements. About one-fifth of the workers had only 2-4 hours of sleep when they were affected by pain. Eighty three per cent of the workers reported the pain in the right and left buttocks and thighs.

\section{Background of jack fruit processing enterprise}

Jack fruit processing enterprise was started by a single man in the year 2000 in Hyderabad with the help of his family members. It was 18 years back old industry and slowly developed it step-by -step as per their own experiences / thoughts. This enterprise was mostly concentrating on making of Jack husk, Jack Pieces, jack fruit chips, jack fruit flour etc. Jack fruits are an important source of carbohydrates, proteins, fibers, minerals like potassium, calcium, and iron; vitamins $\mathrm{A}, \mathrm{B}$ and $\mathrm{C}$.
Jack husk had good proteins and has shelf life of more than 6 months and its quality also depends on packing. These people don't add any chemicals for preservation.

In Andhra Pradesh, it is called as "Panasapottu", Jack pieces are also used in biryani and it has become a compulsory and traditional item in marriages and ceremonies.

This enterprise was also the supplier of jack fruit items to all leading super markets like Reliance, Heritage, Ratnadeep, More etc in Telangana and Andhra Pradesh. They also maintain few own stalls in Rythu Bazar and supply to other caterers.

\section{Types of machinery in jack fruit unit}

Jack fruit processing enterprise was the India's First Industry to make exclusively jack husk and jack pieces by using machinery. These people have developed and designed their own machinery for different tasks with their own ideas and thoughts and also to increase their production and Turnover (Fig. 1).

\section{Results and Discussion}

\section{General Information of workers}

In this jack fruit enterprise, mostly female i.e., above 30 years with 10-15 years of experienced workers were engaged and were illiterate with skill oriented in preparing a jack husk. Workers engaged in this activity, were earning Rs. 5000-10000 per month.

\section{Physical characteristics of workers}

The mean weight and height of the workers was $59.33 \mathrm{~kg}$ and 159.52 respectively with a standard deviation of 3.1 and 5.7.

When BMI was calculated, most of the workers were found with normal weight. 


\section{Workstation assessment}

When workstation of jack fruit enterprise was assessed, workers engaged in activity were performing with mechanical aids and machines with a suitable and adjustable height. The workstation was designed in such a way that the workers were able to change their posture according to the activity and they could also reduce or eliminate bending or twisting posture of the wrist. The workers could reach above the shoulder line with a static muscle loading with their completely extended arms.

Workstation did not allow full range of movements when engaged in the activity and the edges of the work surface were sharp and angled. Armrest and footrest were not provided wherever it was needed.

In this workstation there was not enough natural lighting to perform the task without stress and completely depended on artificial lighting. The workplace was with uncomfortable temperature and noise. Cushioned floor mats and chair or stools were not provided for workers to stand or sit for longer period of time while working.

\section{Low back pain assessment}

Low back pain (LBP) is a common symptom and represents a serious public health problem. More than $80 \%$ of the general population was affected with low back pain in the industrialized world because of uncomfortable workstation and posture that are adopted by them. It is the most frequent cause of disability in people under 45 years of age.

Oswestry low back pain disability questionnaire was used to collect the information about low back pain experienced by the workers. It consisted of ten sections but nine sections were only considered for the present study i.e. pain intensity, personal care, lifting, walking, sitting, standing, sleeping, social life and travelling. Impact on sex life was not studied due to difficulty in questioning them. Each section comprised of 6 statements by assigning score from 0 for no pain, 1 to mild pain, 2 to moderate pain, 3 to fairly severe pain, 4 to very severe pain and 5 to worst pain. Thus it has a total score of maximum 45 and minimum zero. Based on the obtained scores, level of disability was calculated by using the formula Obtained score/total possible score x 100.

Disability percentage ranged from 28 to $47 \%$ for the workers which indicated that the workers were having moderate to severe disability which requires a detailed investigation.

Further analysis revealed that the workers in jack fruit enterprise were experiencing low back pain between $1-5$ days for every 2 weeks and also suffering with foot and ankle pain in both right and left leg even when in sitting posture also. When trying to bend forward, the workers could touch their mid thighs with the tips of their fingers without bending the knees.

When questioned them about pain experienced in the last two weeks, the workers reported that they were able to sit in chair and stand as long as they wanted without any extra pain and they had only 2-4 hours of sleep due to their work stress.

\section{Health hazards encountered at workplace}

In this enterprise, More or less an equal per cent of the workers reported that they were suffering from cough, sneezing, eye irritation, cataract, itching, cuts, and hearing problems from excess noise, muscle pain and discomfort. 
Fig.1 Types of machinery in jack fruit unit
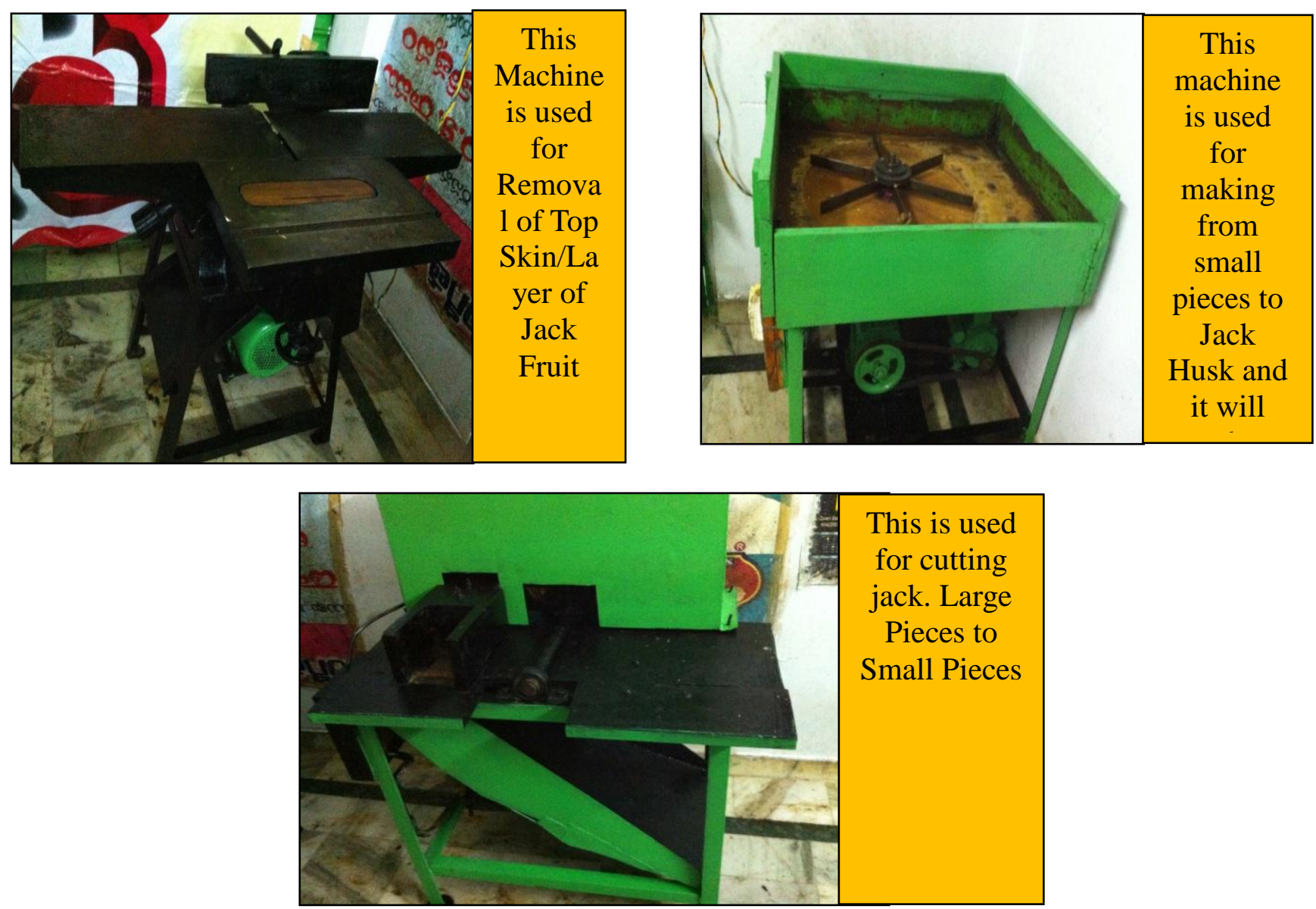

Personal protective and controlling measures

Majority of the workers were using personal protective measures at work viz., Apron, Gloves, Shoes/boots, Hat and also controlling the environment by using fire extinguisher, vaccum cleaner, and proper electrical fittings. Trapping and nets were used to control the pest. In this processing enterprise, open dumping and waste bin method were used for disposal of waste.

So concluded, Jack fruit is processed mainly to reduce the post harvest losses and to increase the shelf life of it. Since processing was a laborious process, very few industries are existent in the city. One such enterprise in Hyderabad city was identified and studied the work station design and its impact on health condition of the workers. Their work involved sitting and standing postures due to which low pain was experienced by the workers. Environmental parameters like temperature, light and noise were not comfortable for the workers. Care needs to be taken to improve working environment conditions and to reduce the low back pain by keeping machinery at height as per their anthropometric dimensions so that they need not bend in an incorrect posture.

\section{Acknowledgement}

The authors sincerely thank the participants of the study, without which this wouldn't have been possible. 


\section{References}

Ajayi, I.A. (2008). Comparative study of the chemical composition and mineral element content of Artocarpus heterophyllus and Treculia africana seeds and seed oils. Bioresource Technology 99(11): 5125-5129.

Elevitch Craig R. And Manner Harley I., 2006, Artocarpus heterophyllus L. (Jackfruit), ver. 1.1v. In: Elevitch, C.R. (Ed.). Species Profiles for Pacific Island Agro forestry. Permanent Agriculture Resources (PAR), Holualoa, Hawai, i. $1-17$.

Fazi, H.M., Mohamed, N.M.Z.N., Rashid, M.F.F.A and Rose, A.N.M. 2016. Ergonomics study for workers at food production industry. MATEC Web of conferences 90. DOI:10.1051/ matecconf/20179001003.
Logeswari, S., Parimalam, P., Hemalatha, G and Geetha, P.S. 2013. Musculoskeletal discomforts in papad industry. Ergonomics for rural development. 379385.

Priya, G., Vasanti, J., Rachana, D., Savita, R., Ashok, S and Parag, S. 2017. Prevalence of musculoskeletal disorders in restaurant workers. Indian journal of physical therapy. 5(1):16-19.

Tiwari, R.R. 2015. Situational analysis of occupational health issues of restaurant and dhaba workers. Occupational medicine and health affairs. 3(6):1-4. doi:10.4172/2329-6879.1000224.

Vijayalakshmi, V., Deepika, J and Milcah paul, M. 2018. Impact of workstation on health of handloom weavers in Nalgonda district. The pharma innovation journal. 7(9): 44-48.

\section{How to cite this article:}

Vijaya Lakshmi, V. and Deepika, J. 2018. A Case Study on Workers' Perception about Workstation and Its Impact on Their Health in Jack Fruit Processing Enterprise. Int.J.Curr.Microbiol.App.Sci. 7(12): 1809-1814. doi: https://doi.org/10.20546/ijcmas.2018.712.211 